\title{
The Influence of Gender Role on Gender Segregation of STEM Majors in Chinese Universities
}

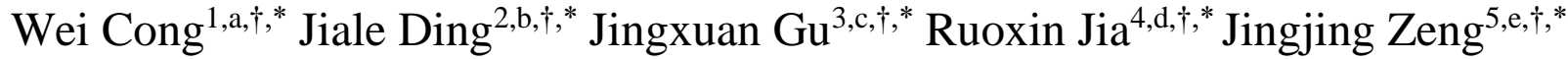

\author{
${ }^{1}$ Hebei University of Science and Technology, Shijiazhuang, Hebei (050000), China \\ ${ }^{2}$ University of British Columbia, Vancouver, British Columbia (V6T1Z4), Canada \\ ${ }^{3}$ Nanjing Normal University, Nanjing, Jiangsu (210046), China \\ ${ }^{4}$ East China Normal University, Shanghai (200062), China \\ ${ }^{5}$ Waseda University, Toshima, Tokyo (1710033), Japan \\ *Corresponding author.Email: abetty.cw@foxmail.com, bdingjiale2017@126.com, $05170231 @ n j n u . e d u . c n$, \\ d10180350240@stu.ecnu.edu.cn, ${ }^{e}$ zengjingjing@toki.waseda.jp \\ These authors contributed equally.
}

\begin{abstract}
Science and technology are the primary productive forces of a country. However, in today's STEM (Science, Technology, Engineering, and Mathematics) fields, gender segregation remains an issue. Half of the world's population is female, yet women face considerable barriers and are underrepresented in STEM education and occupations. This article mainly focuses on STEM education, to explore how gender role is shaped and reinforced in high school and how it leads to gender segregation of STEM majors in Chinese universities. The findings show that gender stereotype leads female students to devalue self-cognition and self-assessment and, as a result, they often underestimate their ability in STEM disciplines. Second, the educational policy in high school causes female students to prioritize liberal art subjects at the expense of natural science subjects. Third, high school curriculum, textbooks, and other teaching materials that contain gender bias and unhealthy teacher-student interactions reinforce the stereotype of gender role. Fourth, the decisions of majors are strongly affected by traditional Chinese culture that represents the preferences and career expectations for different genders. At the end of this article, implications will be provided.
\end{abstract}

Keywords: Gender role, Gender segregation, STEM, High school

\section{INTRODUCTION}

STEM (Science, Technology, Engineering, and Mathematics) fields are always being sought after and loved by people worldwide. STEM fields are indispensable to the industrialization and economic development of a country. In the wave of economic globalization in the 21st century, STEM education has become an important factor in economic competition, and every country is trying to engage students in STEM fields. Empirical evidence suggests that the larger the number of STEM graduates, the larger the country's GDP growth rate in terms of dollars [1]. Improving teaching and learning in STEM education has been regarded as a powerful means of boosting the economy by developing countries, emerging economies, and long-established economies such as Europe and the United States [2].
However, gender segregation is prevalent in STEM fields. There is still an apparent distinction regarding gender. Women remain underrepresented in STEM education and STEM occupations, which is a kind of implicit gender discrimination. Female students show relatively low interest in STEM majors. For some countries whose female graduates in all fields are more than half, males still constitute a majority of graduates in the area of engineering, manufacturing, and construction. And men continue to predominate in research jobs. For the percentage of women among researchers, it is even lower than $25 \%$ in many countries. Women face considerable barriers and unfair treatment like less income, fewer chances of being promoted, and consistently rank lower in the science system [3].

In China, a Report on the Development of Human Resources in China's Science and Technology (2018) 
indicates that women account for about $40 \%$ of China's human resources of science and technology, which is higher than the global [4]. Yet, many of them are at the grassroots level, and high-level female scientific research talents are scarce. According to the Fourth National Survey on the Status of Scientific and Technological Workers, about $31.7 \%$ of women reported that they had suffered gender discrimination, such as being less able to obtain professional training opportunities than men [5]. The survey data released by the Mycos survey agency shows that among Chinese university graduates in 2009 , most of the males were in science and engineering majors, while the females were mainly in liberal arts majors [6][7].

Current researches focus on the differentiation results and practical influences of gender segregation. Wang (2016) discovers obvious gender segregation in the social work field, and $\mathrm{Li}$ (2010) put forward suggestions on vocational education for female college students in STEM subjects from the perspective of gender segregation [8][9]. However, there are few researches on the causes of gender segregation in STEM majors by exploring back to the students' high school period, especially in China. All China's high schools have implemented a discipline-specific policy. At the end of the first year of high school, students need to choose one of the liberal arts or sciences to study in the latter two years. This policy aims to narrow the areas of education for students to better master more knowledge in a certain field [10]. When choosing a university major, only science high school students can choose STEM majors due to policy restrictions. Also, students take the college entrance examination and determine the majors shortly. In some schools, almost half of college students choose a job that corresponds to their major when they graduate [11]. Besides, educational goals with different treatments toward genders, bias from classmates, expectations from teachers, and school environment all lead to this phenomenon [12-14]. Therefore, it can be said that the high school period is the most critical period for female students to decide whether to choose STEM majors in the university.

Gender socialization theory suggests that isolation is endogenously formed through acquired systems and cultural influences in society [15]. The formation of gender roles is mainly the result of social and cultural construction [16]. A Female's low status is not a congenital reason but a result of acquired education. It is imposed on them by social, historical, and cultural customs. Feingold uses meta-analysis methods, proving no statistically significant difference between the two sexes in cognitive abilities [17].

Therefore, this study aims to examine how gender roles are shaped and reinforced in high school period and how traditional gender role leads to gender segregation of STEM majors in Chinese universities.
Studying the influence of traditional gender roles on gender segregation in STEM majors in Chinese universities is conducive to promoting the equality of all genders and the harmonious development of society [18].

\subsection{Gender role}

Gender role indicates the fixed thoughts and behaviours assigned by society (men should go out and earn money for their family, women should stay at home and do the housework; boys should be interested in cars and girls should play dolls, etc.). The concept could limit male/female's potential and increase the otherness of male and female. For instance, common gender stereotypes worldwide suggest that men are good at STEM majors and women are more likely to choose non-STEM majors, making STEM majors more like a gendered concept. Besides, research suggests that men are believed to be more agentic and competent than women, whereas women are believed to be more communal than men [19]. Furthermore, in China, men are encouraged in STEM majors, women are more likely to choose non-STEM majors including arts or education majors under the influence of the gender stereotypes.

\subsection{Gender Segregation}

Gender Segregation is an extensive form of gender discrimination that is often intertwined and reinforced by gender stereotypes. In kindergarten, teachers make the concept of gender salient would cause more gender biases and stereotypes to the opposite sex, affect their further socialization process since same-sex socialization seems like there are fewer differences between each other. Segregation is often affected by gender stereotypes that prevent males and females from obtaining ideal majors or occupations if they choose opposite-gendered major/occupation due to biases. Females are underrepresented in male-dominated majors (STEM fields' majors) but overrepresented in social sciences fields [20]. Also, research suggests that women could outperform men academically [21] but still experienced disadvantages in the career and labour market [22].

\section{DISCUSSION}

\subsection{Gender roles shaped and reinforced in high school}

Female students are less enrolled in STEM-related subjects and self-underestimate their math ability in high school. The male stereotype of science and a scientist appears in kindergarten age [23]. It is not surprising that female students in high school are less likely to choose science subjects that are not their 
“domain". In turn, a low proportion of women in STEM leads to the spread of a gender stereotypical image of math and science as male domains [24]. Widespread gender perceptions can influence girls' perceptions of their abilities in STEM fields, causing them to evaluate themselves as less competent in subjects such as math and science [25]. Several studies have shown that selfassessments of mathematics ability are generally lower in female students and influence STEM degree choice [26][27]. Thus, the stereotype that STEM is males' major and females and that females are naturally poor at STEM is reinforced.

The educational policy that divides natural science and liberal art subjects has exacerbated the less participation in STEM-related subjects. Most Chinese high school students are divided into arts (politics, history, and geography) or science (physics, chemistry, and biology) in grade 10 or 11 . Art students only have exams for language, math, English, and arts subjects in the college entrance examination. Because of this, art students only have opportunities to participate in science in their first year. What's worse, students who have decided to choose art before the division will not take those subjects that are not in their college entrance exams seriously, leading to less participation in science.

Gender stereotypes can be shaped by gender bias in the high school curriculum, textbooks, and other teaching materials. The curriculum is the core of education and the most powerful tool for transmitting and transforming society's culture, values, and beliefs to students. Because textbooks play a dominant role in delivering curricula, depictions of males and females in textbooks influence students' views of gender. Unfortunately, the roles of girls and women are underrepresented in textbooks and curricula. Taiwanese scholars have categorized gender bias in textbooks into four types: disproportionality, stereotyping, biased neglect, and linguistic bias [28]. Empirical research of Chinese high school language textbooks using text analysis and questionnaire survey found imbalanced gender ratio of authors, low proportion of typical female characters, and stereotypical characters of female characters [29]. Another empirical analysis of illustrations in physics textbooks in Chinese middle school revealed gender differences in male and female characters' frequency of appearance, status, age, occupation, and personality [30]. Students always have faith in textbooks. This stereotypical representation misleads students to believe that males are more suitable for science [31].

High school teachers' interactions with students also matter as a social situational context in which widely shared beliefs about gender are challenged or reinforced. Ridgeway and Correll (2004) refer to the sex composition of student-teacher interactions, which can implicitly evoke gender beliefs and influence role enactment and performance evaluation [32]. A teacher plays a very important part in school education, and their ideas and beliefs can change the thought patterns of young students. The actions and words of a teacher will help to shape a child's view of gender roles. It is the teachers' responsibility to create a learning environment without stereotypical gender role beliefs. Lack of sensitivity about the gender issue is not difficult to find in teachers, resulting in reinforced gender stereotypes and poorer performance of female students. RiegleCrumb and Humphries (2012) found evidence of variation across course-level contexts in regard to high school teachers' bias in the assessment of boys' and girls' math ability [33]. The study of Thomas (2017) showed teacher's implicit science-is-male stereotype could contribute to gender differences in female students' motivational beliefs [34].

To summarize, the STEM-is-male stereotype can be reinforced or challenged in high school by girls' enrollment in science and math courses, education system, textbooks, and teachers. Generally speaking, educational gender stereotypes about STEM subjects get more persistent during the high school period. Furthermore, since masculine work contexts form an important source of social identity threat for working women (Van et al., 2019), high school girls who are establishing career orientations probably prefer STEM fields less as educational gender stereotypes are closely related to occupational gender stereotypes.

\subsection{Gender role leading to gender segregation of STEM majors in universities}

Although the gender differences in STEM achievement are proved to be rather small, women still are missing in STEM fields, and STEM fields are dominated by males [35]. In contrast, social determinists believe that based on the traditional gender prevalent in education, female students have weaker motivation to study STEM majors. By considering the influence of Confucianism, an ancient Chinese belief system, a great number of Chinese people still support the traditional gender role. This system of thoughts and behaviours requires a person to act like a man or woman that should be in order to serve their purpose for the country. Therefore, it is the official political theory of ancient Imperial China since the Han dynasty. In the Confucianism cultural values, men are expected to support their families, be loyal and useful to their country. Being loyal and useful to their country means being the soldiers who can protect the country or be the bureaucrats to serve the country. And if a man wants to be a bureaucrat, he must attend Chinese imperial examinations (so called keju). However, the imperial examinations and the schools are only for males. By rejecting female students and female bureaucrats, the social norms believe that women are not made for study. 
On the other hand, women are expected to be loyal and supportive to their male family members (her father, her brothers, her husband, or even her sons), do their best to be good wives, and raise their children. And since women have to answer to their male family members, they are considered as property, so they don't have the right to inherit property. For this reason, people prefer male children. Thus, women support men, and men dominate their families, then the heads of the families (men) serve the country. The Confucianism social moralities combined with the imperial system are patriarchy, systemically oppressed and degraded women for thousands of years.

Modern China had already abolished the imperial system in 1911. However, traditional cultural values still exist. For example, people still think men are good at science, engineering, and math. They are better than women, while women are good at literature and art. Also, men are encouraged to do what they want to do, be brave and bold. Meanwhile, women are supposed to have a stable and easy job, and that is enough, then get married, be good mums at a suitable age. Many Chinese parents support these kinds of traditional gender roles. Therefore, the career expectations from families based on the traditional gender norms affect female students' career choices more than male students' [36].

So do the teachers in universities. College teachers pass gender stereotypes to female students, even when female students do better in STEM majors, so female students receive more traditional gender stereotypes than male students. Also, gender bias is in the education system, like the lack of same-gender model in class, education model based on traditional gender roles, or sexism male students and male teachers. Hence, female students lack motivation in STEM fields.

\section{CONCLUSION}

\subsection{Conclusion}

To conclude, our paper mainly focused on how traditional gender roles and gender stereotypes influence high school students in China and how this phenomenon caused gender segregation and then impact their major choice. This paper also states how China differs from other country's educational systems, including the arts and science division, which is a unique policy that differs from other countries. Furthermore, gender segregation in STEM majors would contribute to further differentials of two genders, including careers and status. Ultimately, our finding states that it is necessary to make a change in the educational system and the importance of gender equity promotion.

\subsection{Implications}

Traditional gender role belief is influencing the gender segregation of STEM majors in Chinese universities along with other factors, and there are some implications that this study can give to the field of education. Firstly, teachers should give their students some right guide on their major choice. We should also try our best to eliminate the gender inequity in teaching materials. In addition, we should set more female role models in STEM fields to encourage them.

\section{REFERENCES}

[1] Podobnik, B., Christopher Crawford, G., Lichtenstein, B., Lipic, T., Wild, D., Zhang, X., \& Stanley, H. E. (2020). The new wealth of nations: How STEM fields generate the prosperity and inequality of individuals, companies, and countries. Chaos, Solitons \& Fractals, 141, N.PAG. DOI: https://doi.org/10.1016/j.chaos.2020.110323

[2] Kennedy, T. J., \& Odell, M. R. L. (2014). Engaging students in stem education. Science Education International, 25, 246-258.

[3] UNESCO. (2012). World atlas of gender equity in education. Paris, France: United Nations Educational, Scientific and Cultural Organization.

[4] China Association for Science and Technology. (2020). China Science and Technology Human Resources Development Research Report (2018) -Total amount, structure and flow of science and technology human resources: https://www.cast.org.cn/art/2020/8/18/art_80_1311 $\underline{10}$

[5] China Association for Science and Technology [CAST]. (2017). The Fourth National Survey Report on the Status of Scientific and Technological Workers (2017): https://www.cast.org.cn/art/2017/8/28/art_150_ $\underline{23576}$

[6] Mycos Data Corporation. (2010). Survey of Job Seeking and Work Ability of 2009 Chinese University Graduates: http://www.mycos.com.cn

[7] Ceci, S. J., \& Williams, W. M. (n.d.). Understanding current causes of women's underrepresentation in science. Proceedings of the National Academy of Sciences of the United States of America, 108(8), 3157-3162. DOI: https://doi.org/10.1073/pnas.1014871108

[8] Wang, W. Q. (2016). The Sex Segregation in the Field of Social Work. Social Work, 3, 112-113.

[9] Li, X. J. (2010). From the perspective of gender segregation, the career development education 
of female students in science and engineering college. Journal of Jiamusi Institute of Education, 3, 17-18.

[10] Liu, Z. J., \& Wang, Z. C. (2009). Terminating the Division of the Artsand Science in Senior High Schools The Battle between the Necessity and the Possibility. Curriculum - Textbook - Teaching Method, 29(9), 3-8.

[11] Fu, Y. H. (2013). Analysis report on the relevance and adaptability of graduate employment positions and majors. Journal of Chifeng Institute of Education, 29(7), 178-179.

[12] Mann, A., \& DiPrete, T. A. (n.d.). Trends in gender segregation in the choice of science and engineering majors. Social Science Research, 42(6), 1519-1541. DOI: https://doi.org/10.1016/j.ssresearch.2013.07.002

[13] Leaper, C., \& Starr, C. R. (n.d.). Helping and Hindering Undergraduate Women's STEM Motivation: Experiences With STEM Encouragement, STEM-Related Gender Bias, and Sexual Harassment. Psychology of Women Quarterly, 43(2), 165-183. DOI: https://doi.org/10.1177/0361684318806302

[14] P. Stromquist. (2007). The Gender Socialization Process in Schools: A Cross-National Comparison. Education for All Global Monitoring Report 2008.

[15] Eccles, J. S. (n.d.). Award for distinguished scientific applications of psychology: Jacquelynne S. Eccles. American Psychologist, 72(9), 889-891. DOI: https://doi.org/10.1037/amp0000269

[16] Lewis, M. (1), \& Weinraub, M. (2). (n.d.). Origins of early sex-role development. Sex Roles, 5(2), 135-153. DOI: https://doi.org/10.1007/BF00287927

[17] Feingold, A. (1988). Matching for attractiveness in romantic partners and same-sex friends: A metaanalysis and theoretical critique. Psychological Bulletin, 104(2), 226-235. DOI: https://doi.org/10.1037/0033-2909.104.2.226

[18] Hill, C., Corbett, C., \& Rose, A. S. (2010). Why So Few? Women in Science, Technology, Engineering, and Mathematics. American Association of University Women. 1111 Sixteenth Street NW, Washington, DC 20036.

[19] Thébaud, S., \& Charles, M. (n.d.). Segregation, stereotypes, and STEM. Social Sciences, 7(7). DOI: https://doi.org/10.3390/socsci7070111

[20] Barone, C. (1), \& Assirelli, G. (2). (n.d.). Gender segregation in higher education: an empirical test of seven explanations. Higher Education, 79(1), 55-78. DOI: https://doi.org/10.1007/s10734-01900396-2

[21] Di Prete, T. A., \& Buchmann, C. (n.d.). The rise of women: The growing gender gap in education and what it means for American schools (Vol. 9781610448000). Russell Sage Foundation.

[22] Bobbitt-Zeher, D. (1,2). (n.d.). The gender income gap and the role of education. Sociology of Education, $\quad 80(1), \quad 1-22 . \quad$ DOI: https://doi.org/10.1177/003804070708000101

[23] Makarova, E., Aeschlimann, B., \& Herzog, W. (2019). The gender gap in stem fields: the impact of the gender stereotype of math and science on secondary students' career aspirations. Frontiers in Education, $\quad 10, \quad 60 . \quad$ DOI: https://doi.org/10.3389/feduc.2019.00060

[24] Nosek, B. A. (1), Banaji, M. R., \& Greenwald, A. G. (n.d.). Math $=$ male, me $=$ female, therefore math $\neq$ me. Journal of Personality and Social Psychology, 83(1), 44-59. DOI: https://doi.org/10.1037/0022-3514.83.1.44

[25] Du, X. (2020). Views of Roles Played by Two Genders in the Expectations of Adolescents in Science-Related Career-Empirical Analysis of Gender- Based Stereotypes in Mathematics. Journal of China Women's University, 032(002), 84-93. DOI: 10.13277/j.cnki.jcwu.2020.02.013

[26] Correll, S. J. (1,2). (n.d.). Gender and the career choice process: The role of biased self-assessments. American Journal of Sociology, 10(6), 1691-1730. DOI: https://doi.org/10.1086/321299

[27] Perez-Felkner, L. (1), McDonald, S.-K. (1), Schneider, B. (2), \& Grogan, E. (3). (n.d.). Female and male adolescents' subjective orientations to mathematics and the influence of those orientations on postsecondary majors. Developmental Psychology, 48(6), 1658-1673. DOI: https://doi.org/10.1037/a0027020

[28] Fang, Z. Y., Xie, W. L., \& Fang, D. L. (2002). Gender Equality Education - Exploration and Practice. Taipei: Wu-Nan Book Inc.

[29] Tang, T. (2017). Research on the Gender Tendency of Chinese Textbooks in Senior High School by PEP. Literature Education, 000(010), 52-53. DOI: 10.16692/j.cnki.wxjyx.2017.10.021

[30] Yu, B., \& Yu, H. B. (2015). Cultural Regeneration of Textbooks-Analysis and Reflection on Gender Culture in Illustrations of Physics Textbooks. Contemporary Education and Culture, 05, 79-83. DOI: 10.13749/j.cnki.cn62-1202/g4.2015.05.017 
[31] Good, J., Woodzicka, J., \& Wingfield, L. (2010). The Effects of Gender Stereotypic and CounterStereotypic Textbook Images on Science Performance. Journal of Social Psychology, 150(2), 132-147.

DOI: https://doi.org/10.1080/00224540903366552

[32] Ridgeway, C., \& Correll, S. (2004). Unpacking the gender system - A theoretical perspective on gender beliefs and social relations. GENDER \& SOCIETY, 18(4), 510-531. DOI: https://doi.org/10.1177/0891243204265269

[33] Riegle-Crumb, C., \& Humphries, M. (n.d.). Exploring Bias in Math Teachers' Perceptions of Students' Ability by Gender and Race/Ethnicity. Gender and Society, 26(2), 290-322. DOI: https://doi.org/10.1177/0891243211434614

[34] Thomas, A. E. (n.d.). Gender Differences in Students' Physical Science Motivation: Are Teachers' Implicit Cognitions Another Piece of the Puzzle? American Educational Research Journal, 54(1), 35-58. DOI: https://doi.org/10.3102/0002831216682223

[35] Yang, X., \& Gao, C. (n.d.). Missing Women in STEM in China: an Empirical Study from the Viewpoint of Achievement Motivation and Gender Socialization. Research in Science Education. DOI: https://doi.org/10.1007/s11165-019-9833-0

[36] Yang, X., \& Gao, C. (n.d.). Missing Women in STEM in China: an Empirical Study from the Viewpoint of Achievement Motivation and Gender Socialization. Research in Science Education. DOI: https://doi.org/10.1007/s11165-019-9833-0 